\title{
Aa. Vv., Paroles et musique
}

\section{Paola Ghinelli}

\section{(2) OpenEdition}

\section{Journals}

\section{Édition électronique}

URL : http://journals.openedition.org/studifrancesi/35301

DOI : 10.4000/studifrancesi.35301

ISSN : 2427-5856

\section{Éditeur}

Rosenberg \& Sellier

\section{Édition imprimée}

Date de publication : 1 novembre 2005

Pagination : 456-457

ISSN : 0039-2944

\section{Référence électronique}

Paola Ghinelli, «Aa. Vv., Paroles et musique », Studi Francesi [En ligne], 146 (XLIX | II) | 2005, mis en ligne le 30 novembre 2015, consulté le 19 avril 2021. URL : http://journals.openedition.org/studifrancesi/ 35301 ; DOI : https://doi.org/10.4000/studifrancesi.35301

\section{Ce document a été généré automatiquement le 19 avril 2021.}

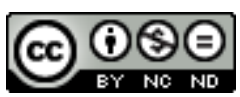

Studi Francesi è distribuita con Licenza Creative Commons Attribuzione - Non commerciale - Non opere derivate 4.0 Internazionale. 


\title{
Aa. Vv., Paroles et musique
}

\author{
Paola Ghinelli
}

\section{RÉFÉRENCE}

«Notre Librairie. Revue des littératures du sud», nº 154, Paroles et musique, avril-juin 2004, pp. 159.

1 Malgré les contraintes imposées par la parution en revue, ce numéro de «Notre Librairie» consacré aux rapports entre musique et littérature parvient à esquisser de nombreuses possibilités de recherche ultérieure. Kangni Alem dans l'éditorial souligne en effet que le travail critique sur ce sujet est encore lacunaire, quoiqu'il existe des travaux sur les liens entre musique et parole dans le domaine des études africaines. Ce numéro est organisé en trois parties principales et il se conclut comme d'habitude avec les nouvelles littéraires, la rubrique bibliographique et des notes de lectures qui se conforment au sujet proposé. La première partie, «convergences», a un caractère plus strictement littéraire et débute avec un article de Rafael Lucas qui est consacré aux littératures afro-caribéennes et à la contamination de ces littératures par la musique, et s'articule en trois modulations. D'abord, il prend en examen l'association littéraire entre la musique et l'histoire, et le rôle de création et de résistance que la musique joue dans plusieurs romans contemporains. Ensuite il décrit les modifications esthétiques que la musique inspire aux écrivains, pour se concentrer finalement sur la transposition littéraire du jazz, du blues, de leur polyphonie et de leur polysémie. Cet article est une excellente introduction au numéro dans son ensemble parce qu'il parvient à toucher quelques éléments essentiels, et qu'il a le mérite de rapprocher des littératures qui sont trop rarement comparées. L'article suivant, de Mukala KadimaNzuji, se concentre sur les deux Congos pour prendre en examen d'autres modulations possibles du lien entre littérature et musique (la chanson de variété notamment) dans la perspective des modalités de production, diffusion et réception de ces deux modes d'expression. L'auteur de l'article suggère d'étudier les textes des chansons de variété comme tout autre texte littéraire. L'œuvre polyvalente de Francis Bebey, le célèbre artiste camerounais, est ensuite interprétée par Fernando Lambert comme un 
rayonnement de sa dimension musicale. Le texte de Ma vie est une chanson est également présenté en conclusion de cet article. Blaise Ndjehoya trace dans sa contribution le lien qui réunit les musiques populaires africaines nées dans l'après-guerre aux rappeurs contemporains, à travers l'analyse des textes, en prenant aussi en considération aussi l'évolution des conditions économiques et sociales dans lesquelles ces chansons se sont diffusées. Jean-Pierre Jacquemin montre les différentes interprétations possibles de la relation entre musique et littérature par l'analyse du lexique «musical» utilisé par Senghor dans l'ensemble de ses poèmes et par l'évocation de Pigments de Léon-Gontran Damas, où la musique, et le jazz en particulier, sont évoqués de manière moins lexicale que rythmique. En conclusion, il cite aussi le romancier Emmanuel Dongala et son hommage à Coltrane. Le dernier article de la section plus ouvertement littéraire de ce numéro de «Notre Librairie» est consacré à la place du chant dans les romans et les pièces de Michèle Rakotoson. Par l'analyse rapprochée de l'œuvre de cette artiste malgache qui vit en France depuis une vingtaine d'années, Dominique Ranaivoson montre encore une fois l'ampleur du sujet choisi, et des possibilités de recherche qu'il offre. La deuxième partie de ce numéro est consacrée au «pool» littéraire et musical congolais mais, loin de fermer la perspective de la première partie, elle en prolonge idéalement les intuitions. Et ainsi, on passe d'un aperçu historique qui confronte l'évolution de la musique «biriveraine» (entre Brazzaville et Kinshasa) avec celle de la littérature, à l'analyse diachronique des textes des chansons en lingala, à celle des influences dans la rumba congolaise. Certains chercheurs se sont aussi penchés sur un artiste particulier: le professeur Levy N'Zienguy sur Jean-Baptiste Tati-Loutard, et sur les différents aspects «musicaux» de sa poésie, et Jean-Barthélemy Bantsimba a interviewé le chanteur Zao, dont on peut lire aussi le texte d'Ancien combattant. La dernière partie de ce numéro, «repères», très riche aussi, privilégie l'aspect musical par rapport à l'aspect littéraire, et elle compte de nombreuses contributions d'auteurs différents qui se concluent avec une interview au rappeur Passi et avec une sélection de cinquante albums de musiques du sud. Ce numéro de «Notre Librairie» est surprenant pour la richesse, la qualité et la diversité des contributions qui le constituent. En outre, il a le mérite d'avoir affronté de manière systématique un sujet vaste et multiforme qui pourrait inspirer les analyses littéraires ponctuelles, profondes et articulées qu'un numéro de revue ne permet pas. 